\title{
Risk factors for anemia in infants assisted by public health services: the importance of feeding practices and iron supplementation
}

\author{
Danielle G. Silva, ${ }^{1}$ Silvia E. Priore, ${ }^{2}$ Sylvia do C. C. Franceschini²
}

\begin{abstract}
Objective: To investigate risk factors for anemia in infants assisted by public health services.

Methods: In a cross-sectional study carried out in Viçosa, state of Minas Gerais, Brazil, 205 children from 6 to 12 months were evaluated. Socioeconomic, environmental and biological data were collected, as well as information on child's birth, nutritional status, maternal data, child health care practices, feeding practices, and iron supplementation. Diagnosis of anemia was based on hemoglobin levels under $11 \mathrm{~g} / \mathrm{dL}$, using a portable Hemocue photometer. To analyze variables associated with anemia, a hierarchical logistic regression model was used.

Results: The prevalence of anemia was $57.6 \%$. Family income per capita less than 0.5 minimum wage, frequency of fruit intake less than daily and lack of iron supplementation increased the chance of anemia among infants.

Conclusion: Adequate health and nutrition support to low income families, promotion of healthy nutritional habits and prescription of iron supplements are of great importance to prevent and manage anemia in infants assisted by public health services.
\end{abstract}

J Pediatr (Rio J). 2007;83(2):149-156: Anemia, iron deficiency, risk factors, infants.

\section{Introduction}

Iron deficiency anemia affects infants at an increasingly earlier age. The growing magnitude of the problem and its impact on child growth, mental and psychomotor development, characterize iron depletion as a major nutritional problem in early life stages. ${ }^{1,2}$

During the first 2 years of life children are at high risk for anemia, considering the reported high prevalence of anemia in infants. ${ }^{3,4}$ Such fact is explained by the rapid growth and the consequent increased demand for iron per kilogram of body weight. In addition, especially after 6 months of age, children need to get increasing amounts of iron from food, which is subject to several absorption limitations. ${ }^{5}$

In Brazil, as well as in other developing nations, anemia affects a significant number of children. In some Brazilian municipalities, prevalences above $60 \%$ have been detected in the first year of life. ${ }^{4,6-8}$ In the city of São Paulo, a secular tendency towards an increasing number of cases of anemia was observed in children under 5 years of age, with a $25 \%$ increase in the years 1984/1985 and 1995/1996. ${ }^{4}$

Biological, socioeconomic, cultural and dietary factors seem to be closely associated with anemia. ${ }^{9}$ Several studies

1. Mestre, Universidade Federal de Viçosa (UFV), Viçosa, MG, Brasil. Doutoranda em Ciências: Nutrição, Universidade Federal de São Paulo (UNIFESP), São Paulo, SP, Brasil.

2. Professora adjunta, Departamento de Nutrição e Saúde, UFV, Viçosa, MG, Brasil. Doutora, Universidade Federal de São Paulo - Escola Paulista de Medicina (UNIFESP-EPM), São Paulo, SP, Brasil.

Financial support: Scholarship from Coordenação de Aperfeiçoamento de Pessoal de Nível Superior (CAPES).

Manuscript received Feb 23 2006, accepted for publication Dec 132006.

Suggested citation: Silva DG, Priore SE, Franceschini SC. Risk factors for anemia in infants assisted by public health services: the importance of feeding practices and iron supplementation. J Pediatr (Rio J). 2007;83(2):149-156.

doi 10.2223/JPED.1603 
indicate age group, ${ }^{6,10-12}$ family income percapita, ${ }^{4,6,11}$ type of milk consumed, ${ }^{8,13,14}$ and concentration of iron in the $\operatorname{diet}^{4,8}$ as the main factors associated with childhood anemia.

In face of the magnitude and severity of anemia in infancy and the importance of understanding its population distribution and etiology, the present study aims at investigating risk factors for anemia in infants assisted by public health services, considering dietary factors.

\section{Methods}

The present study was carried out in the municipality of Viçosa, located in the state of Minas Gerais, Brazil. Viçosa has approximately $300.2 \mathrm{~km}^{2}$ and 64,854 inhabitants, of which 1,057 are children under 1 year of age. In 2000, mortality rates for children under 1 year was 27.56 per 1,000 live births; illiteracy rates were $8.36 \%$ for the population 15 years or older; and $34.29 \%$ of children under 14 years came from families earning less than 0.5 minimum wage. ${ }^{15}$

This study followed a cross-sectional design and was undertaken from July 2002 to April 2003. The sample was constituted of 205 infants from 6 to 12 months who attended public health services after being invited by health personnel or community health agents. Parents or legal guardians were informed about the research procedures before signing a written consent authorizing the child's participation in the study.

The diagnosis of anemia was based on hemoglobin levels. Blood samples were collected by pricking the heel or annular finger (in the case of children who were already walking). Capillary blood samples were collected in a microcuvette, and the portable HemoCue photometer provided a direct reading of the concentration of hemoglobin. A hemoglobin level of 11 $\mathrm{g} / \mathrm{dL}$ was used as a cutoff point for the diagnosis of anemia. ${ }^{1,2}$

Participants were also asked to complete a questionnaire with items on socioeconomic, environmental and biological aspects, as well as maternal characteristics, birth data, information on child health, feeding practices, and iron supplementation.

Weight and length were measured by undergraduate nutrition students, who had been trained by the graduate student responsible for the study, using an electronic scale (Kratos, capacity $15 \mathrm{~kg}$, graduation $5 \mathrm{~g}$ ) and an anthropometric scale (length $120 \mathrm{~cm}$, graduation $0.1 \mathrm{~cm}$ ). Nutritional status was assessed by weight/age and length/age, expressed in z scores, according to the guidelines of the National Center for Health Statistics. ${ }^{16}$

For the dietary assessment, a food frequency questionnaire and 24-hour recall was used. The food frequency questionnaire was qualitative and selective for foods high in iron and enhancers of iron absorption, defined according to local feeding practices. Frequencies were tabulated as daily, weekly ( 1 to 5 times per week) or rarely (less than once a week). The 24-hour recall consisted of all items consumed on the day prior to the interview. This dietary information allowed for the classification of main meals (lunch or dinner) according to iron bioavailability, as presented by Demayer. ${ }^{2}$ Meals with low iron bioavailability contained less than $30 \mathrm{~g}$ of meat or less than $25 \mathrm{mg}$ of ascorbic acid; medium bioavailability meals had between 30 and $90 \mathrm{~g}$ of meat or between 25 and $75 \mathrm{mg}$ of ascorbic acid; high bioavailability meals contained more than $90 \mathrm{~g}$ of meat or more than $75 \mathrm{mg}$ of ascorbic acid, or 30 to $90 \mathrm{~g}$ of meat plus 25 to $75 \mathrm{mg}$ of ascorbic acid.

Data were entered in Epi-Info, version 6.02. Univariate data analysis was also performed, estimating crude odds ratios and their respective confidence intervals.

For data analysis, water supply, sewage and garbage disposal were grouped into a single variable, named "sanitary housing conditions." Lack of any of these items, such as sewage, water supply and/or garbage disposal, resulted in a classification of inadequate sanitary housing conditions, while the presence of all three was classified as adequate. The immunization scheme was classified as incomplete when a delay in the administration of any vaccine was noticed. Morbidity in the last 15 days was identified based on parental reports of flu, cold, diarrhea, infectious diseases, among others. Duration of exclusive breastfeeding was defined as the time period during which infants received only breast milk with no other liquid or solid feeding, except vitamin supplements or prescription drugs. In regard to the type of milk consumed, maternal milk and iron fortified formula were grouped into a single category, as they are associated with a reduced risk of anemia when compared to other types of milk. Intake of breast milk along with other types of non-iron-fortified milk (cow, goat or soy) or consumption of only these types of milk was included in a different category. A low consumption of milk formulas (3.5\%) was observed in this sample. The administration of iron supplements refers to the use of iron medicine during the study period.

A significance level of $20 \%$ was required to enter a variable into the multivariate models, and a significance level of $5 \%$ was required to indicate a statistically significant association. Non-conditional hierarchical logistic regression was used for multivariate analysis in SPSS version 10.0. Hierarchical modeling has been used and recommended for investigating risk factors in epidemiological studies. ${ }^{17}$ In setting up a theoretical hierarchical model of anemia, the following items were included in the analysis: at the first level, socioeconomic and environmental conditions; at the second level, biological characteristics, nutritional status, maternal characteristics, birth data, and child health; at the third level, feeding practices; and at the fourth level, iron supplementation practices. Variables that showed significant 
association at higher levels continued to be part of lower level models, even when not reaching statistical significance.

The present study was submitted to and approved by the Research Ethics Committee of the Universidade Federal de Viçosa.

\section{Results}

The prevalence of anemia in the 205 children studied was $57.6 \%(n=118)$. Among anemic children, 41.5\% $(n=49)$ had hemoglobin levels below $9.5 \mathrm{mg} / \mathrm{dL}$.

Results of the univariate analysis of the association between anemia and other investigated variables are shown in Tables 1, 2 and 3.

As presented in Table 1, among the variables regarding socioeconomic and environmental conditions, only family income per capita was associated with the presence of anemia. Infants from families with an income of less than 0.5 minimum wage had a 2.54 greater chance of having anemia when compared to those from families earning more than 0.5 minimum wage.

Variables related to biological characteristics, nutritional status, maternal information, birth data, and child health were not statistically associated with anemia (Table 2 ).

Among feeding practices, eating red meat and the frequency of eating liver and fruit were statistically associated with anemia (Table 3 ).

Iron supplementation was strongly associated with anemia (Table 3). Children who did not receive iron supplements had a 2.37 greater chance of having anemia than those who received iron supplements.

Table 4 shows the results of the hierarchical logistic regression for anemia. In the first hierarchical block, family income per capita, even after adjusting for sanitary housing conditions, remained statistically associated with anemia

Table 1 - Distribution of anemic and non-anemic infants, crude odds ratio, and respective $95 \%$ confidence intervals according to socioeconomic and environmental factors, Viçosa, MG, 2002-2003

\begin{tabular}{|c|c|c|c|c|c|c|c|}
\hline Variables & $\mathbf{n}$ & Anemic & Non-anemic & $\%$ anemia & Crude OR & $95 \% \mathrm{CI}$ & $\mathbf{p}$ \\
\hline $\begin{array}{l}\text { Income per capita } \\
\text { (minimum wage) }\end{array}$ & 200 & & & & & & \\
\hline$\geq 0.5$ & & 17 & 25 & 40.5 & 1 & & \\
\hline$<0.5$ & & 100 & 58 & 63.3 & 2.54 & $1.19-5.43$ & 0.007 \\
\hline Maternal education (years) & 204 & & & & & & \\
\hline$>4$ & & 52 & 46 & 53.1 & 1 & & \\
\hline$\leq 4$ & & 65 & 41 & 61.3 & 1.40 & $0.77-2.54$ & 0.233 \\
\hline Household size & 204 & & & & & & \\
\hline$<4$ & & 29 & 28 & 50.9 & 1 & & \\
\hline$\geq 4$ & & 89 & 58 & 60.5 & 1.48 & $0.77-2.87$ & 0.209 \\
\hline Sanitary housing conditions & 205 & & & & & & \\
\hline Adequate & & 98 & 78 & 55.7 & 1 & & \\
\hline Inadequate & & 20 & 9 & 69.0 & 1.77 & $0.71-4.47$ & 0.179 \\
\hline Father living at home & 205 & & & & & & \\
\hline Yes & & 95 & 66 & 59.0 & 1 & & \\
\hline No & & 23 & 21 & 52.3 & 0.76 & $0.37-1.57$ & 0.423 \\
\hline
\end{tabular}

$95 \% \mathrm{CI}=95 \%$ confidence interval; OR $=$ odds ratio. 
Table 2 - Distribution of anemic and non-anemic infants, crude odds ratio, and respective $95 \%$ confidence intervals according to biological characteristics, nutritional status, maternal information, birth data, and child health, Viçosa, MG, 2002-2003

\begin{tabular}{|c|c|c|c|c|c|c|c|}
\hline Variables & $\mathbf{n}$ & Anemic & Non-anemic & $\%$ anemia & Crude OR & $95 \% \mathrm{CI}$ & $\mathbf{p}$ \\
\hline Age (months) & 205 & & & & & & \\
\hline $9 \mid-12$ & & 59 & 48 & 55.1 & 1 & & \\
\hline $6 \mid-9$ & & 59 & 39 & 60.2 & 1.23 & $0.68-2.23$ & 0.463 \\
\hline Sex & 205 & & & & & & \\
\hline Female & & 49 & 46 & 51.6 & 1 & & \\
\hline Male & & 69 & 41 & 62.7 & 1.58 & $0.87-2.89$ & 0.107 \\
\hline Weight/age index (z score) & 205 & & & & & & \\
\hline$\geq-1$ & & 88 & 55 & 61.5 & 1 & & \\
\hline$<-1$ & & 30 & 32 & 48.4 & 0.59 & $0.31-1.12$ & 0.080 \\
\hline Length/age index (z score) & 205 & & & & & & \\
\hline$\geq-1$ & & 82 & 57 & 59.0 & 1 & & \\
\hline$<-1$ & & 36 & 30 & 54.5 & 0.83 & $0.44-1.57$ & 0.547 \\
\hline Maternal age (years) & 204 & & & & & & \\
\hline$\geq 20$ & & 96 & 71 & 57.5 & 1 & & \\
\hline$<20$ & & 22 & 15 & 59.5 & 1.08 & $0.50-2.38$ & 0.825 \\
\hline Birth order & 203 & & & & & & \\
\hline First born & & 50 & 44 & 53.2 & 1 & & \\
\hline Second born or later & & 66 & 43 & 60.6 & 1.35 & $0.74-2.45$ & 0.290 \\
\hline Duration of pregnancy (months) & 204 & & & & & & \\
\hline 9 & & 111 & 82 & 57.5 & 1 & & \\
\hline $8-7$ & & 7 & 4 & 63.6 & 1.29 & $0.33-5.46$ & 0.471 \\
\hline Birth weight (g) & 203 & & & & & & \\
\hline$\geq 3,000$ & & 72 & 54 & 57.1 & 1 & & \\
\hline $2,500 \mid-3,000$ & & 34 & 28 & 54.8 & 0.91 & $0.47-1.76$ & 0.764 \\
\hline$<2,500$ & & 10 & 5 & 66.7 & 1.50 & $0.44-5.39$ & 0.479 \\
\hline Child caretaker & 205 & & & & & & \\
\hline Mother & & 91 & 72 & 55.8 & 1 & & \\
\hline Other & & 27 & 15 & 64.3 & 1.42 & $0.67-3.05$ & 0.323 \\
\hline Immunization scheme & 205 & & & & & & \\
\hline Complete & & 106 & 84 & 55.8 & 1 & & \\
\hline Incomplete & & 12 & 3 & 80.0 & 3.17 & $0.79-14.83$ & 0.067 \\
\hline Morbidity in the last 15 days & 203 & & & & & & \\
\hline Absent & & 45 & 36 & 55.6 & 1 & & \\
\hline Present & & 72 & 50 & 59.0 & 1.15 & $0.63-2.11$ & 0.625 \\
\hline
\end{tabular}

$95 \% \mathrm{CI}=95 \%$ confidence interval; OR = odds ratio. 
$(\mathrm{OR}=2.45 ; 95 \% \mathrm{CI} 1.22-4.93)$. Sex, weight/age index and immunization scheme - variables with a p value below 0.20 in the univariate analysis - did not show a statistically significant association with anemia, when controlling for family income per capita. Among variables related to feeding practices, the only one that remained significant after adjustment for family income per capita was frequency of fruit intake $(\mathrm{OR}=1.88 ; 95 \% \mathrm{CI} 1.03-3.42)$. Intake of red

Table 3 - Distribution of anemic and non-anemic infants, crude odds ratio, and respective $95 \%$ confidence intervals according to feeding and supplementation practices, Viçosa, MG, 2002-2003

\begin{tabular}{|c|c|c|c|c|c|c|c|}
\hline Variables & $\mathbf{n}$ & Anemic & Non-anemic & $\%$ anemia & Crude OR & $95 \% \mathrm{CI}$ & $\mathbf{p}$ \\
\hline $\begin{array}{l}\text { Duration of exclusive breastfeeding } \\
\text { (days) }\end{array}$ & 205 & & & & & & \\
\hline$\geq 60$ & & 62 & 52 & 54.4 & 1 & & \\
\hline$<60$ & & 56 & 35 & 61.5 & 1.75 & $0.41-1.36$ & 0.303 \\
\hline Type of milk & 205 & & & & & & \\
\hline $\begin{array}{l}\text { Breast milk and/or iron-rich } \\
\text { formulas }\end{array}$ & & 31 & 21 & 59.6 & 1 & & \\
\hline $\begin{array}{l}\text { Breast milk and non-iron-rich milk } \\
\text { or only non-iron-rich milk }\end{array}$ & & 87 & 66 & 56.9 & 0.89 & $0.45-1.77$ & 0.728 \\
\hline Frequency of beans intake & 205 & & & & & & \\
\hline Daily & & 100 & 71 & 58.5 & 1 & & \\
\hline Less than daily & & 18 & 16 & 52.9 & 0.80 & $0.36-1.78$ & 0.550 \\
\hline Intake of red meat & 205 & & & & & & \\
\hline Yes & & 81 & 72 & 52.9 & 1 & & \\
\hline No & & 37 & 15 & 71.2 & 2.19 & $1.05 ; 4.61$ & 0.021 \\
\hline Frequency of red meat intake & 205 & & & & & & \\
\hline Daily or weekly & & 63 & 58 & 52.1 & 1 & & \\
\hline Less than weekly & & 55 & 29 & 65.5 & 1.75 & $0.95-3.23$ & 0.056 \\
\hline Intake of liver & 205 & & & & & & \\
\hline Yes & & 46 & 37 & 55.4 & 1 & & \\
\hline No & & 72 & 50 & 59.0 & 1.16 & $0.63-2.12$ & 0.609 \\
\hline Frequency of liver intake & 205 & & & & & & \\
\hline Weekly & & 10 & 16 & 38.5 & 1 & & \\
\hline Less than weekly & & 108 & 71 & 60.3 & 2.43 & $0.97 ; 6.16$ & 0.034 \\
\hline Intake of fruit & 205 & & & & & & \\
\hline Yes & & 113 & 84 & 57.4 & 1 & & \\
\hline No & & 5 & 3 & 62.5 & 1.24 & $0.25-6.75$ & 0.537 \\
\hline Frequency of fruit intake & 205 & & & & & & \\
\hline Daily & & 55 & 58 & 48.7 & 1 & & \\
\hline Less than daily & & 63 & 29 & 68.5 & 2.29 & $1.29 ; 4.06$ & 0.004 \\
\hline Intake of dark-green vegetables & 205 & & & & & & \\
\hline Yes & & 65 & 52 & 55.6 & 1 & & \\
\hline No & & 53 & 35 & 60.2 & 1.21 & $0.67-2.21$ & 0.502 \\
\hline Number of main meals & 205 & & & & & & \\
\hline Two & & 70 & 53 & 56.9 & 1 & & \\
\hline One or none & & 48 & 34 & 58.5 & 1.07 & $0.58-1.96$ & 0.817 \\
\hline Bioavailability of iron in the diet & 204 & & & & & & \\
\hline High or medium & & 30 & 31 & 49.2 & 1 & & \\
\hline Low & & 88 & 55 & 61.5 & 1.65 & $0.86-3.18$ & 0.101 \\
\hline Use of iron supplements & 205 & & & & & & \\
\hline Yes & & 18 & 26 & 40.9 & 1 & & \\
\hline No & & 100 & 61 & 62.1 & 2.37 & $1.13-4.98$ & 0.011 \\
\hline
\end{tabular}


meat and frequency of intake, frequency of liver intake, and bioavailability of iron in the diet were not significant in the multivariate model, and were withdrawn from the analysis. Intake of iron supplements was associated with anemia (OR = $2.39 ; 95 \%$ CI 1.17-4.90), independently from variables in previous blocks (family income per capita and frequency of fruit intake).

\section{Discussion}

In accordance with data from the literature, the present study revealed a high prevalence of anemia (57.6\%) among infants. However, it is important to emphasize that these data are from a convenience sample, composed by children seen at public health services after parental agreement to take part in the study. This could have overestimated the actual prevalence of anemia, since participation in the study may have been higher among families suspecting that their children had anemia. On the other hand, prevalence studies of anemia based on representative samples of Brazilian municipalities have found similar or even higher frequencies than found in this sample. ${ }^{4,6-8}$ Thus, the frequency found for this sample may actually represent the true prevalence of anemia for infants in Viçosa. The fact that $41.5 \%$ of anemic infants had hemoglobin levels below $9.5 \mathrm{~g} / \mathrm{dL}$ shows the intensity of iron deficiency in this group, which can result from early depletion of iron stores and long duration of anemia. Considering that the first 2 years of life carry the highest risk for developing anemia, an important public health strategy would be to promote an early detection and diagnosis of anemia in the first year of life, aiming at early treatment and preventive measures.

In the studied population, predominantly of low socioeconomic status, family income per capita proved to be an important risk factor for anemia. Nevertheless, high frequencies of anemia were found in both income categories (above and below 0.5 minimum wage). Several studies have found family income per capita to be the main distal determinant in causality models of anemia.4,6,11 Despite being present in all socioeconomic groups, the prevalence of anemia tends to be lower in upper classes. ${ }^{18}$ The low buying power of families can be related to reduced food availability and variety, resulting in insufficient intake and low

Table 4 - Results of the hierarchical logistic regression model, Viçosa, MG, 2002-2003

\begin{tabular}{|c|c|c|c|c|c|}
\hline Model & Crude OR & Adjusted OR & $95 \% \mathrm{CI}$ adjusted OR & p (variable) & p (model) \\
\hline \multicolumn{6}{|c|}{ Socioeconomic factors* } \\
\hline \multicolumn{6}{|l|}{$\begin{array}{l}\text { Income per capita } \\
\text { (minimum wage) }\end{array}$} \\
\hline$\geq 0.5$ & 1 & 1 & & & \\
\hline$<0.5$ & 2.53 & 2.45 & $1.22-4.93$ & 0.012 & 0.018 \\
\hline \multicolumn{6}{|l|}{ Feeding practices $^{\dagger}$} \\
\hline \multicolumn{6}{|c|}{ Frequency of fruit intake } \\
\hline Daily & 1 & 1 & & & \\
\hline Less than daily & 2.29 & 1.88 & $1.03-3.42$ & 0.039 & 0.003 \\
\hline \multicolumn{6}{|c|}{ Iron supplementation ${ }^{\neq}$} \\
\hline \multicolumn{6}{|c|}{ Intake of iron supplements } \\
\hline Yes & 1 & 1 & & & \\
\hline No & 2.37 & 2.39 & $1.17-4.90$ & 0.017 & 0.001 \\
\hline
\end{tabular}


bioavailability of nutrients, including iron. In addition, being exposed to unfavorable living conditions, these families are more vulnerable to respiratory infections, diarrhea and intestinal parasitosis, which cause an increased demand and reduced absorption of nutrients. ${ }^{3,9}$ In regard to birth conditions, prematurity and low birth weight are described as important risk factors for anemia, since reduced iron stores at birth and the early depletion of iron stores play a role in the development of anemia. ${ }^{19}$ In the present study, however, such association was not found, possibly due to the small number of children presenting these characteristics (15 low birth weight and 11 premature infants). Some authors suggest that because prematurity and low birth weight unlike iron deficiency - have low prevalences, they should not be considered important determinants for early anemia in infants. ${ }^{18}$ Other studies did not find a link between low birth weight and anemia. ${ }^{10,11,14}$

Feeding practices seem to be strictly related to the presence of anemia in childhood. As in most populations, anemia is caused mainly by iron deficiency, the present study focused on the relationship between anemia and intake and frequency of intake of iron-rich food and enhancers of iron absorption. Some feeding practices have been emphasized as having a significant impact on the development of anemia. These include short duration of exclusive breastfeeding, consumption of cow milk, late introduction and insufficient dietary intake of iron sources, such as meat, as well as enhancers of iron absorption, such as fruit. ${ }^{3,5}$ The intensity of such effects can vary according to population characteristics and local or regional feeding practices.

Cow's milk consumption has been identified as a main determinant of anemia in the first year of life. ${ }^{4,14}$ As in the present study, other previous research did not find an association between duration of exclusive breastfeeding and/or type of milk consumed and anemia. 6,11,12 The impact of exclusive breastfeeding on anemia may be more evident in infants until the age of 6 months.

In the studied sample, among the variables related to feeding practices, a less than daily frequency of fruit intake almost doubled the chance of having anemia. After the sixth month of life, the intake of fruit is considered essential, because of its mineral and vitamin content, especially ascorbic acid. Ascorbic acid enhances iron absorption by facilitating the reduction of the ferric ion to the ferrous state, which is more soluble, and also inhibits the formation of insoluble complexes of iron and other constituents of the diet that prevent the absorption of this mineral. ${ }^{20}$ Studies using stable isotopes to estimate the bioavailability of iron in foods served to 9 month old infants showed that fruit juices containing $50 \mathrm{mg}$ of ascorbic acid increased up to 2 times the bioavailability of iron from food. ${ }^{21}$ In developing countries, especially in low income populations, as the one investigated in this study, most dietary iron comes from plant food, that is, non-heme iron, which is easily influenced by other components of the diet. ${ }^{2,20}$ Thus, if in the studied population the daily intake of fruit occurs close to main meals this could be contributing to a higher bioavailability of the iron consumed. Meat is, in general, considered to be an excellent source of iron, mainly for the high bioavailability of heme iron, in addition to enhancing iron absorption from other dietary sources in a meal. Nevertheless, meat is expensive, which limits its access to low income families. In the present study, the intake of red meat was not statistically associated with anemia in the multiple regression model. Similarly, in a cross sectional study with 362 children under 6 years of age seen at public health services in the outskirts of Pelotas (state of Rio Grande do Sul, Brazil), no association was found between anemia and weekly intake of meat and liver. ${ }^{12}$ On the other hand, the protective effect of meat intake was demonstrated by a study with 8 month old children in which higher hemoglobin levels were found in the group that consumed 27 $\mathrm{g}$ of meat per day during 2 months, compared to a group that ate $10 \mathrm{~g} /$ day. $^{22}$

Corroborating results found in the present study, the importance of feeding practices was demonstrated in a prospective study with children under 24 months from families with low socioeconomic status in the city of São Paulo, Brazil. Both the intake of milk formulas at the fourth month of life and the intake of vitamin $\mathrm{C}$, meats and beans at the sixth month were found to be the main protective factors against anemia. ${ }^{23}$

Although appropriate feeding practices contribute to the maintenance of an adequate iron nutrition status in childhood, the need of an additional source of iron during the first 2 years of life is unquestionable, whether by iron medicine or iron-rich food. ${ }^{5}$ In places where the prevalence of anemia is high and most food served to infants and preschoolers is not iron fortified, iron supplements should be a priority in the prevention of anemia. ${ }^{24}$ Recently, in 2005, the Brazilian Health Ministry instituted the National Program on Iron Supplementation, designed to fight iron deficiency anemia among children, pregnant women and infants, especially through iron medicine. In the present study, the absence of iron supplements was strongly associated with anemia, reinforcing the importance of iron supplementation to prevent this deficiency in infants. Among children who were receiving iron supplements, only $22.7 \%(n=10)$ had previously taken a blood test, suggesting that most of them were using iron supplements in prophylactic doses. It is important to emphasize that less than half of children evaluated were receiving iron supplements, a strategy recommended by the Brazilian Society of Pediatrics. Among infants receiving iron supplements, $40.9 \%(n=18)$ had anemia, possibly indicating inadequate frequency and/or 
insufficient doses of iron supplements. Therefore, current practices of iron supplementation need to be investigated, aiming at improving the effectiveness of iron supplementation in the control of anemia.

Finally, this study indicates that the main determinants of anemia among infants assisted by the public health services of Viçosa (MG) are family income per capita, frequency of fruit intake and intake of iron supplements. Therefore, family income below 0.5 minimum wage, less than daily intake of fruit and absence of iron supplementation are indicative of increased risk of anemia. Thus, effective control of anemia in public health services requires assistance to health and nutrition practices of low income families; nutritional education to motivate appropriate feeding habits and adequate introduction of complementary food; early diagnosis and treatment of anemia; and implementation of routine prophylactic supplementation with iron, including dose standardization and adherence monitoring.

\section{Acknowledgements}

To the city hall of Viçosa and to nutritionist Nerilda M. M. Lima, for their support in the execution of the study. To the workgroup "Anemia Project", for their assistance in data collection. To professor Marilene Euclydes, for suggestions concerning dietary analysis.

\section{References}

1. World Health Organization. Iron deficiency anaemia. Assessment, prevention, and control. A guide for programme managers. Geneva: WHO/UNICEF/UNU; 2001.

2. Demayer EM. Preventing and controlling iron deficiency anaemia through primary health care. Geneva: WHO; 1989.

3. Sigulem DM, Tudisco ES, Goldenberg P, Athaide MMM, Vaisman E. Anemia ferropriva em crianças do município de São Paulo. Rev Saude Publica. 1978;12:168-78.

4. Monteiro CA, Szarfarc SC, Mondini L. Tendência secular da anemia na infância na cidade de São Paulo (1984-1996). Rev Saude Publica. 2000;34:62-72.

5. Stekel A. Iron nutrition in infancy and childhood. New York: Raven; 1984.

6. Neuman NA, Tanaka OY, Szarfarc SC, Guimarães PRV, Victoria CG. Prevalência e fatores de risco para anemia no sul do Brasil. Rev Saude Publica. 2000;34:57-63.

7. Osório MM, Lira PI, Batista-Filho M, Ashworth A. Prevalence of anemia in children 6-59 months in the state of Pernambuco Brazil. Rev Panam Salud Publica. 2001;10:101-7.

8. Hadler MC, Colugnati FA, Sigulem DM. Risks of anemia in infants according to dietary iron density and weight gain rate. Prev Med. 2004;39:713-21.

9. Szarfarc SC, Souza SB. Prevalence and risk factors in iron deficiency and anemia. Arch Latinoam Nutr. 1997;47:35-8.
10. Murila FV, Macharia WM, Wafula EM. Iron deficiency anaemia in children of a peri-urban health facility. East Afr Med J. 1999;76:520-3.

11. Silva LSM, Giugliani ERJ, Aerts RGC. Prevalência e determinantes de anemia em crianças de Porto Alegre, RS, Brasil. Rev Saude Publica. 2001;35:66-73.

12. Santos I, César JA, Minten G, Valle N, Neumann NA, Cercato E. Prevalência e fatores associados à ocorrência de anemia entre menores de seis anos de idade em Pelotas, RS. Rev Bras Epidemiol. 2004;7:403-15.

13. Mira M, Alperstein G, Karr M, Ranmuthugala G, Causer J, Niec A, et al. Haem iron intake in 12-36 month old children depleted in iron: case-control study. BMJ. 1996;312:881-3.

14. Male C, Persson LA, Freeman V, Guerra A, van'tHof MA, Haschke $F$, et al. Prevalence of iron deficiency in 12-mo-old infants from 11 European areas influence of dietary factors on iron status (Euro-Growth study). Acta Paediatr. 2001;90:492-8.

15. Instituto Brasileiro de Geografia e Estatística. Síntese de indicadores sociais 2000. Estudos e Pesquisas. Informação demográfica e socioeconômica. n.5. Rio de Janeiro: IBGE; 2001.

16. Hamill PV, Drizd TA, Johnson CL, Reed RB, Roche AF. NCHS Growth curves for children birth-18 years. United States. Vital Health Stat. 1977;11:1-74.

17. Fuchs SC, Victora CG, Fachel J. Modelo hierarquizado: uma proposta de modelagem aplicada à investigação de fatores de risco para diarréia grave. Rev Saude Publica. 1996;30:168-78.

18. Monteiro CA, Szarfarc SC. Estudo das condições de saúde das crianças no município de São Paulo, SP (Brasil), 1984-1985. Anemias. Rev Saude Publica. 1987; 21:255-60.

19. Lawson M. Iron in infancy and childhood. In: The British Nutrition Foundation. Iron. Nutritional and physiological significance. Report of British Nutrition Foundation Task Force. London: Chapman and Hall; 1995. p. 93-105.

20. Bianchi MLP, Silva HC, Oliveira JED. Considerações sobre a biodisponibilidade do ferro nos alimentos. Arch Latinoam Nutr. 1992;42:94-100.

21. Fairweather-Tait S, Fox T, Wharf SG, Eagles J. The bioavailability of iron in different weaning foods and the enhancing effect of a fruit drink containing ascorbic acid. Pediatr Res. 1995;37:389-94.

22. Engelmann MD, Sandström B, Michaelsen KF. Meat intake and iron status in late infancy: an intervention study. J Pediatr Gastroenterol Nutr. 1998;26:26-33.

23. Urrestarazu Devincenzi M, Basile Colugnati FA, Sigulem DM. Factores de protección para la anemia ferropriva: estudio prospectivo en niños de bajo nivel socioeconómico. ALAN. 2004; $54: 174-9$.

24. United Nations Children's Found, United Nations University, World Health Organization, MI Technical Workshop. Preventing iron deficiency in woman and children: background and consensus on key technical issues. New York: INF/MI; 1998.

Correspondence:

Sylvia do C. C. Franceschini

Departamento de Nutrição e Saúde

Universidade Federal de Viçosa, Campus Universitário

CEP 36571-000 - Viçosa, MG - Brazil

Tel. : +55 (31) 3899.1275, +55 (31) 3899.2536

E-mail: sylvia@ufv.br 